\title{
FC $\gamma$ Chimeric Receptor-Engineered T Cells: Methodology, Advantages, Limitations, and Clinical Relevance
}

\section{OPEN ACCESS}

Edited by:

Ignacio Melero,

University of Navarra, Spain

Reviewed by:

Francisco Borrego,

BioCruces Health Research

Institute, Spain

Julian Pardo,

Fundación Agencia Aragonesa para la Investigación y el

Desarrollo (ARAID), Spain

Luis Alvarez-Vallina,

Aarhus University, Denmark

*Correspondence:

Giuseppe Sconocchia

giuseppe.sconocchia@cnr.it

${ }^{\dagger}$ Present address:

Tommaso Sconocchia, Institute of Pathophysiology and Immunology, Medical University

of Graz, Graz, Austria

Specialty section:

This article was submitted

to Cancer Immunity

and Immunotherapy,

a section of the journal

Frontiers in Immunology

Received: 03 February 2017 Accepted: 04 April 2017

Published: 27 April 2017

Citation:

Caratelli S, Sconocchia T, Arriga R, Coppola A, Lanzilli G, Lauro D, Venditti A, Del Principe MI,

Buccisano F, Maurillo L, Ferrone $S$ and Sconocchia G (2017) FC

Chimeric Receptor-Engineered

T Cells: Methodology, Advantages, Limitations, and Clinical Relevance.

Front. Immunol. 8:457.

doi: 10.3389/fimmu.2017.00457

\author{
Sara Caratelli', Tommaso Sconocchia ${ }^{1 \dagger}$, Roberto Arriga ${ }^{2}$, Andrea Coppola ${ }^{2}$, \\ Giulia Lanzilli ${ }^{1}$, Davide Lauro ${ }^{2}$, Adriano Venditti ${ }^{3}$, Maria Ilaria Del Principe ${ }^{3}$, \\ Francesco Buccisano ${ }^{3}$, Luca Maurillo ${ }^{3}$, Soldano Ferrone ${ }^{4}$ and Giuseppe Sconocchia ${ }^{1 *}$ \\ 'Institute of Translational Pharmacology, CNR, Rome, Italy, ${ }^{2}$ Department of Systems Medicine, University of Rome \\ "Tor Vergata", Rome, Italy, ${ }^{3}$ Department of Biomedicine and Prevention, University of Rome "Tor Vergata", Rome, \\ Italy, ${ }^{4}$ Departments of Surgery and of Orthopedic Surgery, Massachusetts General Hospital, Harvard Medical School, \\ Boston, MA, USA
}

For many years, disappointing results have been generated by many investigations, which have utilized a variety of immunologic strategies to enhance the ability of a patient's immune system to recognize and eliminate malignant cells. However, in recent years, immunotherapy has been used successfully for the treatment of hematologic and solid malignancies. The impressive clinical responses observed in many types of cancer have convinced even the most skeptical clinical oncologists that a patient's immune system can recognize and reject his tumor if appropriate strategies are implemented. The success immunotherapy is due to the development of at least three therapeutic strategies. They include tumor-associated antigen (TAA)-specific monoclonal antibodies (mAbs), T cell checkpoint blockade, and TAA-specific chimeric antigen receptors (CARs) T cell-based immunotherapy. However, the full realization of the therapeutic potential of these approaches requires the development of strategies to counteract and overcome some limitations. They include off-target toxicity and mechanisms of cancer immune evasion, which obstacle the successful clinical application of mAbs and CAR T cell-based immunotherapies. Thus, we and others have developed the Fc gamma chimeric receptors (Fcy-CRs)-based strategy. Like CARs, Fcy-CRs are composed of an intracellular tail resulting from the fusion of a co-stimulatory molecule with the $T$ cell receptor $\zeta$ chain. In contrast, the extracellular CAR single-chain variable fragment (scFv), which recognizes the targeted TAA, has been replaced with the extracellular portion of the FcyRIIIA (CD16). Fcy-CR T cells have a few intriguing features. First, given in combination with mAbs, Fc $\gamma$-CR T cells mediate anticancer activity in vitro and in vivo by an antibody-mediated cellular cytotoxicity mechanism. Second, CD16-CR T cells

\footnotetext{
Abbreviations: ADCC, antibody-dependent cellular cytotoxicity; ADCP, antibody-dependent cellular phagocytosis; ATL, adult T cell leukemia; BC, breast cancer; BLCL, B lymphoblastoid cell line; CAR, chimeric antigen receptor; CCR4, CC chemokine receptor 4; CDC, complement-dependent cytotoxicity; CLL, chronic lymphocytic leukemia; CRC, colorectal carcinoma; CTL, cytotoxic T cell; DC, dendritic cell; EC, extracellular; EGFR, epidermal growth factor receptor; Fcy-CR, Fc gamma chimeric receptor; FR $\alpha$, folate receptor alpha; HL, Hodgkin lymphoma; HN, head and neck; IC, intracellular; IFN $\gamma$, interferon gamma; IgG, immunoglobulin G; IL-12, interleukin-12; IL-15, interleukin-15; mAb, monoclonal antibody; MHC, major histocompatibility complex; MM, multiple myeloma; Mog, mogamulizumab; NHL, non-Hodgkin lymphoma; NK, natural killer; NSCLC, non-small-cell lung carcinoma; OC, ovarian cancer; PBMC, peripheral blood mononuclear cell; PTCL, peripheral T-cell lymphoma; RCC, renal cell carcinoma; scFv, single-chain variable fragment; TAA, tumor-associated antigen; TCR, T cell receptor; TGF $\beta$, transforming growth factor beta; TM, transmembrane.
} 
can target multiple cancer types provided that TAA-specific mAbs with the appropriate specificity are available. Third, the off-target effect of CD16-CR T cells may be controlled by withdrawing the mAb administration. The goal of this manuscript was threefold. First, we review the current state-of-the-art of preclinical CD16-CR T cell technology. Second, we describe its in vitro and in vivo antitumor activity. Finally, we compare the advantages and limitations of the CD16-CR T cell technology with those of CAR T cell methodology.

Keywords: antitumor activity, chimeric antigen receptor T cells, CD16-CR T cells, CRC, Fc gamma chimeric receptor, hematologic malignancies, immunotherapy, solid tumor

In 1989, Gross and colleagues introduced the concept of engineering $\mathrm{T}$ cells with chimeric receptors capable of overcoming the major histocompatibility complex restriction, laying the groundwork to generate a powerful tool for targeted cancer immunotherapy (1). The chimeric antigen receptors (CARs) are molecules capable of redirecting cytotoxic T cells (CTLs) against a tumor-associated antigen (TAA) expressed on the surface of malignant cells. A CAR typically consists of a single-chain variable fragment ( $\mathrm{scFv}$ ) derived from the antigen binding region of a TAA-specific $\mathrm{mAb}$ linked to the $\mathrm{T}$ cell receptor (TCR)-associated CD3 $\zeta$-chain signaling domain (2). This structure refers to the first generation of CAR. In vitro and in vivo studies, performed using $\mathrm{CD} 3 \zeta$-CARs, showed promising results demonstrating an efficient tumor cell elimination. However, the following clinical trials failed to confirm the first generation CAR-T cell therapeutic efficacy, although a first-generation CAR targeting GD2 induced complete remission of neuroblastoma in 3 out of 11 pediatric patients (3). These data indicated that a single activating signal mediated by the TCR $\zeta$ chain is not sufficient to obtain a full activation of $\mathrm{T}$ cells as far as persistence, cytokine release, and proliferation is concerned $(4,5)$. To overcome the first-generation CAR-T cell limitations, the co-stimulatory endodomain of CD28 molecule was added to the intracellular tail of CD3 3 -CARs (6); these chimeras were referred to as second generation CARs (7) (Figure 1). Second-generation CARs improved T cell functions by providing $\mathrm{T}$ cells with a stronger signal to avoid $\mathrm{T}$ cell anergy and apoptosis after antigen binding. The superior activity of the second generation over the first generation CARs was demonstrated in vitro and in vivo models $(8,9)$. Preclinical data about the superiority of second generation CAR over the first generation were then corroborated by clinical results $(10,11)$. In addition, there is evidence that the incorporation of $\mathrm{CD} 28$ co-stimulatory domain into CARs may avoid some of the mechanisms that tumor cells utilize to escape from T cells. Indeed, compared to the first generation of CAR T cells, (i) CD28-CAR T cells secrete higher levels of interferon gamma (IFN $\gamma$ ); (ii) efficiently eradicate transforming growth factor beta (TGF $\beta$ ) producing tumor cells; and (iii) suppress TGF $\beta$ inhibition of T cell expansion $(12,13)$.

The enhancement of $\mathrm{T}$ cell activation by the usage of costimulatory molecules, into the first generation of CAR was also

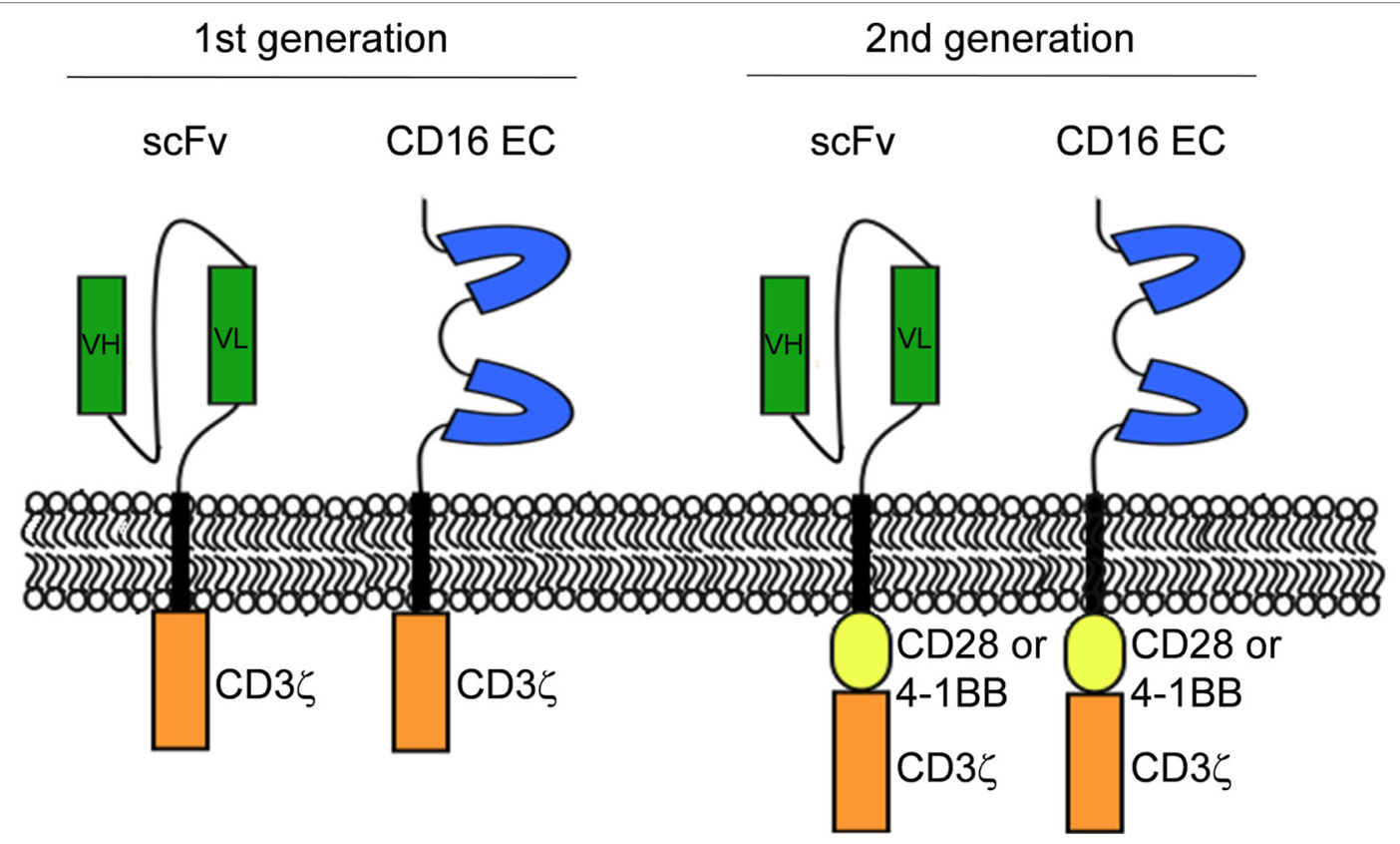

FIGURE 1 | Schematic representation of CD16-CR and classical chimeric antigen receptor molecular structures. The first generation of CR has the extracellular domain linked to the intracellular signaling motif of $\mathrm{CD} 3 \zeta$ chain while the second generation of $\mathrm{CR}$ has an additional co-stimulatory endodomain derived from $\mathrm{CD} 28$ or $4-1 \mathrm{BB}$ linked to the $\mathrm{N}$-terminal of $\mathrm{CD} 3 \zeta$ chain. 
described by additional studies in which the CD28 molecule was fused in tandem or replaced with 4-1BB (14). Tammana et al. (15) redirected umbilical cord blood $\mathrm{T}$ cells to eliminate, in vitro and in vivo, both lymphoma and leukemia cells by transducing

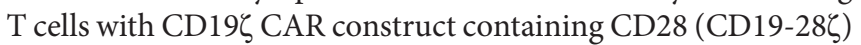
or $4-1 \mathrm{BB}(\mathrm{CD} 19-\mathrm{BB} \zeta)$ or a combination of both (CD19-28BB $\zeta)$ co-stimulatory molecules fused with $\zeta$ chain in the intracellular domain. They demonstrated that CD19-BBל CAR T cells and CD19-28BB $\zeta$ exhibited the highest cytotoxic activity against CD19 positive leukemia and lymphoma cell lines. Interestingly, treatment with $\mathrm{CD} 19-28 \mathrm{BB} \zeta$ prolonged the survival of lymphomabearing mice to a greater extent than treatment with $\mathrm{CD} 19-\mathrm{BB} \zeta$ CAR $\mathrm{T}$ cells, indicating that $4-1 \mathrm{BB}$ molecule enhances the co-stimulatory properties of the CD28 molecule in umbilical cord blood $\mathrm{T}$ cells. In a second study, Song et al. (16) assessed the impact of 4-1BB co-stimulatory signaling on in vivo persistence, tumor localization, and antitumor activity of CAR $\mathrm{T}$ cells in epithelial cancer. They constructed two CARs containing a folate receptor alpha $(\mathrm{FR} \alpha) \mathrm{scFv}(\mathrm{MOv} 19)$ fused with $\mathrm{CD} 3 \zeta$ alone (MOv19- $\zeta$ ) or in combination with the 4-1BB co-stimulatory domain in tandem (MOv19-BBל). Both MOv19- $\zeta$ and MOv19$\mathrm{BB} \zeta \mathrm{CAR}$ T cells secreted proinflammatory cytokines and exerted cytotoxicity in the presence of $\mathrm{FR} \alpha$ positive cancer cells in vitro. Remarkably, however, only MOv19-BB $\zeta$ CAR T cells mediated persistent infiltration of the ovarian tumor microenvironment leading to tumor regression in immunodeficient mice (16). Thus, the availability of a second generation CAR which contained a 4-1BB signaling domain resulted in an excellent clinical response and prolonged T cell in vivo survival (17). The favorable therapeutic results obtained with the dual-signaling CAR T cells have prompted investigators to hypothesize that the addition of a second co-stimulatory molecule to the CAR would enhance $\mathrm{T}$ cells' antitumor activity. As a result, a third generation CAR composed of two distinct co-stimulatory endodomains was designed. Different combinations of co-stimulatory proteins (e.g. 4-1BB/CD28, CD28/OX40) were assessed, showing various effects concerning $\mathrm{T}$ cell persistence, cytokine release, and tumor regression $(15,18)$.

More recent investigations aimed to boost the therapeutic potential of CAR T cell technology have focused on the development of strategies to arm CAR T cells with tools to counteract immunosuppression mechanism(s) present in the tumor microenvironment. Several strategies have been employed to prevent CAR $\mathrm{T}$ cell depletion by tumors such as genetic modifications to express pro-inflammatory cytokines including interleukin-12 (IL-12) and interleukin-15, chemokine receptors or co-stimulatory ligands (19). CD19-CAR T cells genetically engineered to express IL-12 transgene demonstrated improved survival, stronger cytotoxic function, and significant resistance to Treg inhibition. Furthermore, they favored modulation of tumor-associated immune cells, resulting in high tumor eradication in mouse models (20). In the same way, the CD19-CAR T cells genetically engineered to express CD40L, a tumor necrosis factor superfamily member, displayed enhanced antitumor efficacy against $\mathrm{CD}_{4} 0^{+}$cancer cells, associated with their ability to affect the tumor phenotype by increasing tumor cell sensitivity to Fas-dependent apoptosis and immune destruction (21).
The high antitumor activity displayed by adoptive CAR T cell transfer, during early clinical trials in B cell malignancies, represents a point of strength of this technology. In contrast, CAR T cell-based immunotherapy has demonstrated a limited efficacy with solid tumors. On the other hand, a limitation of this strategy is represented by the reported on-target and off-target toxicity (22). Side effects as cytokine release syndrome and prolonged B-cell depletion were associated with CD19 CAR-T cells infusion (23). The extended in vivo persistence of $\mathrm{T}$ cell transfer may be advantageous as far as anticancer efficacy is concerned but may be harmful to the host. Although many strategies have been implemented to reduce adverse events, such as the introduction of inducible suicide genes (24), interventions aimed to improve CAR-T cell safety remain a priority.

Then, additional therapeutic strategies designed to implement CAR $\mathrm{T}$ cell functions but capable of controlling their toxicity may be underway. One of these strategies involves the Fc $\gamma$-CRs that are atypical CAR composed of the Fc $\gamma$ receptor extracellular domain fused to the intracellular signaling motif of $\mathrm{CD} 3 \zeta$ [Fc gamma chimeric receptor $(\mathrm{Fc} \gamma-\mathrm{CR})]$. A typical example is the extracellular FcyIIIA (CD16)-CR. CD16-CR diverges from the typical CAR structure, due to the replacement of the $s c F v$, which recognizes the targeted TAA with the extracellular region of the CD16. In this context, we will first describe the characteristics of CD16-CRs, and then we will discuss their application in tumor immunotherapy.

\section{THERAPEUTIC MONOCLONAL ANTIBODIES (mAbs) AND Fc $\gamma$ Rs}

In the last decades, steady progress has been made in human cancer treatment with the introduction of therapeutic TAAspecific mAbs. Rituximab (anti-CD20 mAb), trastuzumab (antiHer2/neu $\mathrm{mAb}$ ), and cetuximab [anti-epidermal growth factor receptor (EGFR) $\mathrm{mAb}$ ] represent just some examples of $\mathrm{mAb}$ with demonstrated efficacy in the treatment of B-cell non-Hodgkin lymphoma (NHL), Her2 ${ }^{+}$breast cancers, colorectal carcinoma, and head and neck cancers, respectively $(25,26)$. Recently, many efforts have been made to characterize the mechanisms of action that underlie the clinical success of therapeutic TAA-specific $\mathrm{mAbs}$. Convincing evidence indicates that mAbs exert their antitumor effect by two mechanisms. The first is due to the mAb's ability to interfere with molecular signals involved in malignant cell growth and survival, leading to a direct cell death. The second is immunologic. It is mediated by antibody-dependent cellular cytotoxicity (ADCC) in which mAbs trigger the targeting of cancer cells by innate immune effector cells mainly natural killer (NK) cells (25) and induce or enhance TAA-specific immunity by cognate T cells (27).

The Fc $\gamma$ Rs are a family of surface proteins composed of three classes: Fc $\gamma$ RI (CD64), Fc $\gamma$ RII (CD32), and FcyRIII (CD16) with similar structures but distinct functions. They are widely distributed on the surface of immune cells like NK cells, monocytes, macrophages, dendritic cells (DCs), and B cells (28). When the antibody engages the CD16 on NK cells, it triggers downstream activating pathways resulting in perforin/ granzyme-dependent tumor target cell lysis (29). Several lines of 
evidence suggest the involvement of the Fc $\gamma$ Rs in the antitumor activity of therapeutic mAbs. They include the lower antitumor activity of rituximab and trastuzumab in mice lacking $F c \gamma R$ compared to wild-type mice (30), and the association between CD16 genetic polymorphism with patients' clinical responses to $\mathrm{mAb}$ treatment observed in some malignant diseases $(31,32)$. Notably, the presence of CD16 158-valine allelic polymorphism predicted a better clinical response to rituximab treatment in NHL patients and an improved clinical outcome in colorectal carcinoma patients treated with cetuximab (32). So, evidence coming both from preclinical and clinical studies underlie the high impact of ADCC and FcyRs on mAb anticancer activity. A list of the therapeutic mAbs with demonstrated ADCC activity is reported in Table 1.

The ADCC-mediated clinical success of mAbs is influenced not only by the CD16 allotypes but also by tumor accessibility to cytotoxic cells. In some cases, the tissue architecture may be difficult to reach by the ADCC effector cells such as NK cells, which poorly infiltrate tumor microenvironment (33). In these cases, the ADCC-mediated anticancer activity of $\mathrm{mAbs}$ is reduced. A novel approach useful to overcome this NK cell limitation and to enhance mAbs' cell-mediated cytotoxicity utilizes Fc $\gamma$ CR-engineered T cells since CTLs easily infiltrate the tumor microenvironment and their presence is closely associated with a favorable course of the disease in many types of cancers (34).

\section{CD16-CRs}

Two generations of CD16-CRs have been reported (35-38) (Figure 1). T cells transduced with CD16-CR display antitumor activity only when they are combined with mAbs. Preclinical studies have demonstrated that CD16-CRs trigger cell-mediated cytotoxicity against lymphoma cell lines opsonized with the CD20-specific mAb, rituximab. However, no clinical trials have been conducted to date (Table 2). CD16-CR T cells share with CAR T cells advantages and disadvantages. The former include the ability to mediate an HLA-unrestricted cell-mediated cytotoxicity leading to the elimination of cancer cells with abnormalities in HLA-class I antigen processing machinery component expression and/or function. The latter involve the targeting of a TAA also expressed in normal tissues. However, this atypical CAR brings also three additional advantages compared to classical CARs, although not yet demonstrated. The first one is the possibility to target different types of tumor cells provided that the TAA-specific $\mathrm{mAb}$ with the required specificity are available (Figure 2). The second one is the possibility to improve control of their off-target toxicity, simply by eliminating the supply of mAbs to CD16-CR $\mathrm{T}$ cells through mAb dosage tapering or termination during patient treatment. The third one is the opportunity to mitigate acute toxicity by the administration of high-doses of immunoglobulins. On the other hand, CD16-CR

TABLE 1 | Summary of therapeutic monoclonal antibodies (mAbs) with proved antibody-dependent cellular cytotoxicity (ADCC) activity.

\begin{tabular}{|c|c|c|c|c|}
\hline Name & Target disease & Target antigen & $\begin{array}{l}\text { Immunoglobulin } \\
\text { G (IgG) subclasses }\end{array}$ & Type \\
\hline Rituximab (Rituxan) & Non-Hodgkin lymphoma (NHL) & CD20 & $\lg G 1$ & Chimeric \\
\hline Ofatumumab (Arzerra) & Chronic lymphocytic leukemia (CLL) & CD20 & $\lg \mathrm{l} 1$ & Human \\
\hline Ocaratuzumab & CLL & CD20 & $\lg G 1$ & Humanized \\
\hline Tositumomab (Bexxar) & $\mathrm{NHL}$ & CD20 & $\lg G 2$ & Murine \\
\hline Lucatumumab & $\begin{array}{l}\text { Relapsed CLL } \\
\text { Multiple myeloma (MM), NHL, and } \mathrm{HL}\end{array}$ & CD40 & $\lg G 1$ & Murine \\
\hline Daratumumab (Darzalex) & $\mathrm{MM}$ & CD38 & $\operatorname{lgG} 1$ & Human \\
\hline Alemtuzumab (Campath-1H) & CLL & CD52 & $\lg \mathrm{l} 1$ & Humanized \\
\hline Cetuximab (Erbitux) & $\begin{array}{l}\text { Squamous cell carcinoma } \\
\text { CRC }\end{array}$ & $\begin{array}{l}\text { Epidermal growth factor } \\
\text { receptor (EGFR) }\end{array}$ & $\lg G 1$ & Chimeric \\
\hline Panitumumab (Vectibix) & $\mathrm{CRC}$ & EGFR & $\lg 2_{2}^{a}$ & Human \\
\hline Trastuzumab (Herceptin) & $\begin{array}{l}\mathrm{BC} \\
\mathrm{HER} 2^{+}\end{array}$ & ErbB2 & $\lg G 1$ & Humanized \\
\hline Avelumab & $\begin{array}{l}\text { Bladder cancer, gastric cancer, mesothelioma, non- } \\
\text { small-cell lung carcinoma, ovarian cancer, head and } \\
\text { neck cancer, renal cell carcinoma }\end{array}$ & PDL-1 & $\lg G 1$ & Human \\
\hline Mogamulizumab & Adult T cell leukemia, peripheral T-cell lymphoma & CC chemokine receptor 4 & $\lg G 1$ & Humanized \\
\hline
\end{tabular}

${ }^{a} A n I g G_{2}$ subclass of mAb capable of mediating ADCC by myeloid cells only.

TABLE 2 | Summary of published preclinical studies involving CD16-CR-engineered T cell-based immunotherapy.

\begin{tabular}{|c|c|c|c|c|}
\hline CD16-CRs & Structure & Malignant cells & $\begin{array}{l}\text { Associated monoclonal } \\
\text { antibody }\end{array}$ & Reference \\
\hline $\mathrm{CD} 16 / \gamma$ & CD16 (EC) + FceRl $\gamma$ [transmembrane (TM), IC] & B-lymphoblastoid & Rituximab & Clémenceau et al. (35) \\
\hline CD16 $\zeta$ & $\mathrm{CD} 16(\mathrm{EC})+\mathrm{CD} 3 \zeta(\mathrm{TM}, \mathrm{IC})$ & $\begin{array}{l}\mathrm{CD}^{2} \mathrm{O}^{+} \text {lymphoma, HER2/neu+ } \\
\text { breast cancer, and T cell leukemia }\end{array}$ & $\begin{array}{l}\text { Rituximab } \\
\text { Trastuzumab } \\
\text { Mogamulizumab }\end{array}$ & Ochi et al. (36) \\
\hline CD16V-BB- $\zeta$ & $\mathrm{CD} 16(\mathrm{EC})+\mathrm{CD} 8 \mathrm{a}(\mathrm{TM})+4-1 \mathrm{BB}+\mathrm{CD} 3 \zeta(\mathrm{IC})$ & $\begin{array}{l}\mathrm{CD} 20^{+} \text {, primary B chronic lymphocytic } \\
\text { leukemia, neuroblastoma }\end{array}$ & $\begin{array}{l}\text { Rituximab } \\
\text { Hu14.198K322A }\end{array}$ & Kudo et al. (37) \\
\hline 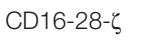 & $\mathrm{CD} 16(\mathrm{EC})+\mathrm{CD} 8 \mathrm{a}(\mathrm{TM})+\mathrm{CD} 28+\mathrm{CD} 3 \zeta(\mathrm{IC})$ & Burkitt's Iymphoma & Rituximab & D'Aloia et al. (38) \\
\hline
\end{tabular}




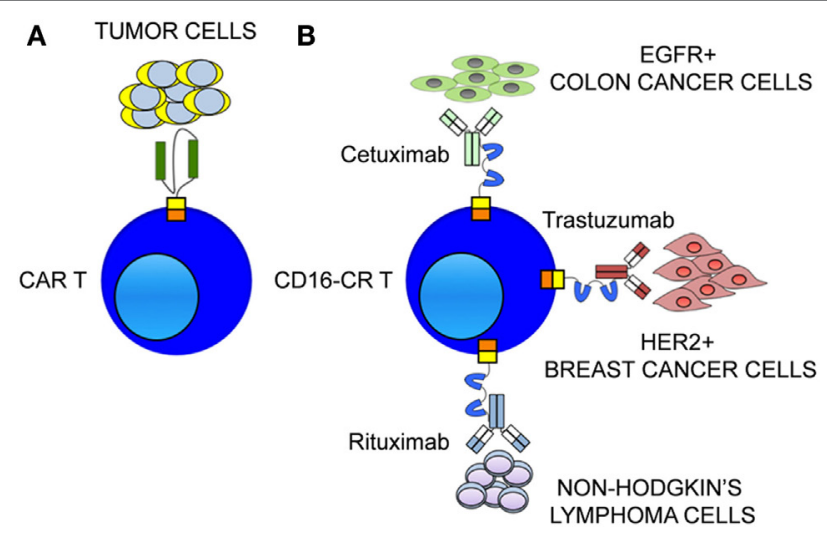

FIGURE 2 | Therapeutic monoclonal antibodies (mAbs) confer to CD16-CR T cells multiple target specificities. (A) The ability of chimeric antigen receptor (CAR) to redirect T cells toward tumor cells is restricted to a single tumor-associated antigen (TAA) expressed on tumor cell surface. (B) The availability of therapeutic mAbs allows CD16-CR to redirect T cells virtually against all TAA expressed on a variety tumor types including hematological and epithelial malignancies.

$\mathrm{T}$ cells bear additional limitations since therapeutic mAbs may compete with serum immunoglobulins for their binding to the Fcy CRs and may be defective in their ability to mediate ADCC. Other potential disadvantages of Fc $\gamma$-CR T cells could be hypothesized when these cells are given to patients with high levels of autoantibodies or viral-specific antibodies following an infectious episode. In the course of autoimmunity, autoantibodies may redirect engineered $\mathrm{T}$ cells against self-antigens. In contrast during an infectious episode, specific-antivirus antibodies could redirect the virus toward engineered $\mathrm{T}$ cells, by the Fc fragments, favoring a viral infection of the cells, which may lead to T cell aberration (39).

\section{FIRST GENERATION OF CD16-CR}

With the goal to utilize cell-mediated cytotoxicity as a mechanism to potentiate the anticancer activity of TAA-specific mAb, Clémenceau and colleagues (35) proposed to engineer T lymphocytes with the first generation of a CD16-CR. They developed a fusion protein composed of the extracellular domain of CD16 ligated to the transmembrane (TM) and the intracellular domain of FceRI $\gamma(\mathrm{CD} 16 / \gamma)$. This construct was utilized to transduce TCR $\alpha \beta$ $\mathrm{CD}^{+}$and $\mathrm{CD}^{+} \mathrm{HLA}-\mathrm{DPB} 1^{\star} 0401$-specific T cells. The cytotoxic activity of the $\mathrm{CD} 16 / \gamma$-T cells was demonstrated in vitro against HLA-DPB $1^{\star} 0401$-positive, and negative B-lymphoblastoid cell lines opsonized with rituximab. Target cell lysis was detected neither with non-transduced T cells against HLA-DPB1 ${ }^{\star} 0401$ negative cell lines nor with CD16/ $\gamma$-transduced $\mathrm{T}$ cells without rituximab. Conversely, in the presence of rituximab, both HLA-DPB $1^{\star} 0401$-positive and negative cell lines were killed at a similar level by transduced $\mathrm{T}$ lymphocytes. Overall, these results indicated the ability of the CD16/ $\gamma$ receptor to trigger T cell cytotoxicity against $\mathrm{mAb}$-opsonized target cells without prior TCR recognition. Furthermore, transduced T cell clones showed active proliferation and cytokine release upon CD16 crosslinking by
mAb-coated target cells. Epstein-Barr virus-specific CTLs were also transduced with the CD16/ $\gamma$-CR and were used to confirm that $\mathrm{CD} 16 / \gamma$-CR expression confers the ability to mediate ADCC both to $\mathrm{CD}^{+}$and $\mathrm{CD} 8^{+} \mathrm{T}$ cells.

The in vitro characterization of the CD16/ $\gamma$-T cells performed by Clémenceau et al. (35) for the first time demonstrated the possibility to transfer the ADCC capacity to T cells. With a similar purpose, later Ochi and collaborators (36) proposed a variant of the CD16-CR obtained by linking the CD16 with the

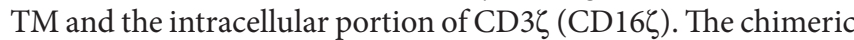
receptor was successfully expressed by lentiviral transduction on T cell surface of a healthy donor, and ADCC activity was reported against $\mathrm{CD} 20^{+}$lymphoma, Her2/neu ${ }^{+}$breast cancer and T-cell leukemia cell lines coated with rituximab, trastuzumab, and mogamulizumab (Mog), respectively. The tumoricidal activity of $\mathrm{CD} 16 \zeta \mathrm{T}$ cells was increased by enhancing the dose of the $\mathrm{mAb}$ and was blocked by a CD16-specific mAb termed 3G8. Following the

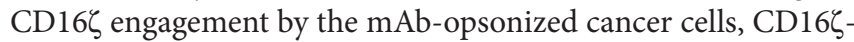
transduced $\mathrm{T}$ cells displayed several functional activities such as IFN $\gamma$ and IL-2 secretion, lytic granule release, and proliferation. Furthermore, Ochi and colleagues assessed the antitumor acti-

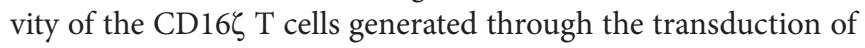
peripheral blood mononuclear cells harvested from $\mathrm{CD} 20^{+} \mathrm{B}$-cell lymphoma patients. They found that CD $16 / \gamma$-T cells exerted antitumor activity against autologous tumor cells to the same extent of healthy donors' transduced $\mathrm{T}$ cells.

The antitumor efficacy of CD16 $\zeta \mathrm{T}$ cells combined with the specific therapeutic $\mathrm{mAb}$ was also validated in vivo. A tumor growth inhibition was reported in B-cell lymphomas immunodeficient xenografted murine model when mice were treated with

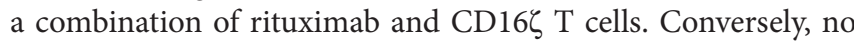
significant tumor mass reduction was observed in mice treated with $\mathrm{CD} 16 \zeta \mathrm{T}$ cells or rituximab alone compared to untreated animals. The overall survival reflected the same pattern: the regimen of $\mathrm{CD} 16 \zeta \mathrm{T}$ cells plus rituximab prolonged mice survival to a significantly greater extent than other treatments. The authors emphasized that CD16 $\zeta \mathrm{T}$ cells have a better in vivo antilymphoma activity than NK cells (36).

Recently, an anti-adult T cell leukemia (ATL) effect has also been reported utilizing $\mathrm{CD} 16 \zeta \mathrm{T}$ cells in association with Mog, an anti-CC chemokine receptor $4 \mathrm{mAb}$ (40). T cells deriving both from healthy donors and ATL patients armed with CD16 -CR exerted a significant ADCC against Mog-coated leukemia cell lines and ATL primary cells. Furthermore, the simultaneous infusion of Mog and CD16 $\zeta$ T cells in ATL xenografted mouse models significantly blocked tumor spread and prolonged mice survival.

Despite the encouraging preclinical results obtained both with the CD16/ $\gamma$ and the CD16 $\zeta$ first-generation CRs, no clinical trials have been conducted yet.

\section{SECOND GENERATION OF CD16-CR}

The second generation of CD16-CR was described both by Kudo et al. (37) and by D'Aloia et al. (38). Kudo et al. generated the CD16V-BB- $\zeta-C R$ by introducing the TM portion of CD8a and the co-stimulatory endodomain of the $4-1 \mathrm{BB}$ into the module of the first-generation $\mathrm{CD} 16 \zeta-\mathrm{CR}$ (37). After CD16V-BB- $\zeta$ 
transduction into $\mathrm{T}$ cells, they investigated the capacity of the CD16-CRs to induce $T$ cell functional activation upon a CD16 receptor crosslinking by an immobilized IgG. They found that CD16V-BB- $\zeta$ engagement promoted IL-2 receptor expression and exocytosis of cytotoxic granules by $\mathrm{T}$ lymphocytes. The $\mathrm{T}$ cells expressing $\mathrm{CD} 16 \mathrm{~V}-\mathrm{BB}-\zeta$-CR were able to mediate granule-dependent ADCC toward $\mathrm{CD} 20^{+}$cell lines and primary $\mathrm{B}$ chronic lymphocytic leukemia cells. About $50-70 \%$ of the target cells were killed in a 4 -h co-culture test. The anticancer efficacy of the CD16V-BB- $\zeta$ T cells, in the presence of the specific therapeutic mAbs, was also demonstrated against solid tumors such as breast and gastric cancer cell lines. Furthermore, the authors validated the tumor regression capacity of the CD16V-BB- $\zeta$ T cells in NOD-SCID IL-2RGnull mice injected with B-cell lymphoma. In all five mice treated with rituximab combined with CD16V-BB- $\zeta$ T cells, a stable remission of the tumor mass was observed after 120 days from the injection. Similar results were reported against xenografted neuroblastoma murine model when hu14.198K322A mAb was used with CD16V-BB- $\zeta$ T cells.

Furthermore, Kudo et al. compared the CD16V-BB- $\zeta-C R$ with the CD16/ $\gamma, \mathrm{CD} 16 \zeta$-CRs, and CD19-CAR demonstrating a superior $\mathrm{T}$ cell activation capacity and antitumor activity of the CD16V-BB- $\zeta$ (37). They also compared the CD16V-BB- $\zeta$ T cells with $\mathrm{T}$ cells transduced with a typical CD19-CAR (CD19-BB- $\zeta)$ regarding cytotoxic effects. They found that target cell elimination was higher with CD16V-BB- $\zeta-C R$ than with CD19-CAR T cells.

While Kudo et al. highlighted the ADCC-mediated antitumor efficacy of the CD16-CR with the co-stimulatory domain of 4-1BB, D'Aloia et al. investigated the ability of a CD16-CR variant carrying the CD28 co-stimulatory motif (CD16-28- $)$ ) (38). They assessed the functionality of the CD16-CR in the MD45 cell line, a murine $\mathrm{T}$ cell hybridoma lacking the lytic granule machinery but with cell killing ability through the Fas/FasL pathway. First, they proved the ability of this chimera to induce MD45 cell activation upon the IgG binding, showing the phosphatidylinositol-3-kinase phosphorylation and IL-2 secretion. The perforin/ granzyme deficient MD45 cell line allowed to test the capacity of CD16-CR to trigger tumor cell depletion by the mediation of Fas/FasL pathway. A 16-h cytotoxicity assay performed with $\mathrm{Fas}^{+}$ Raji lymphoma cells as target cells demonstrated that about $30 \%$ of the tumor cells were lysed by the effector cells, at the highest effector: target ratio, only in the presence of rituximab. A better result regarding the percentage of target cell lysis was reported redirecting MD45-CD16-CR against P815 cells with B73.1, an anti-CD16 mAb, demonstrating that CD16-CR was able to trigger both ADCC and reverse ADCC. Interestingly, the elimination of rituximab-coated Raji cells by MD45-CD16-CR cells was abrogated by an anti-FasL mAb. These results strongly suggest that a Fas/FasL-mediated killing is involved (Figure 3).

\section{FUTURE PERSPECTIVES FOR FC- GAMMA-CR T CELLS}

CD16-CR T cells utilized in combination with TAA-specific mAbs have provided clear evidence of antitumor activity toward hematologic and epithelial malignant cells in vitro and in vivo. The mechanisms by which CD16-CR T cells, in combination with

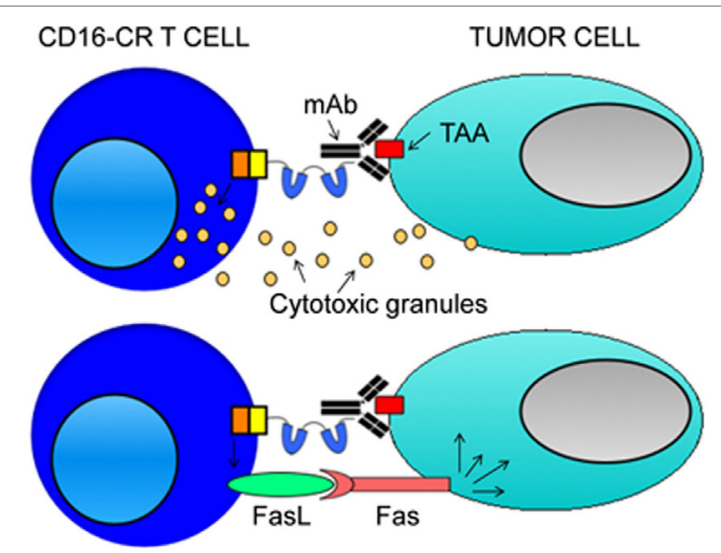

FIGURE 3 | Mechanisms of CD16-CR T cell-mediated tumor cell elimination. CD16-CR T cells acquire the specificity of a monoclonal antibody $(\mathrm{mAb})$ recognizing a tumor-associated antigen (TAA) on the cell surface of tumor cells through the binding of the CD16 with the mAb Fc fragment leading to the activation of T cell-mediated cytotoxicity. In this context, engineered T cells kill tumor cells by using two mechanisms.

The first involves the activation of T cell killing machinery by the release of cytotoxic granules (upper panel). The second arises from the induction of CD16-CR dependent FAS expression on the cell surface of tumor cells that allows FAS ligand positive-engineered T cells to kill tumor cells by a granule independent cellular cytotoxicity (lower panel). However, the latter mechanism is just a hypothetical model based on a single study employing transformed MD45 mouse T cells. Then, the confirmation of the existence of a role for granule independent cytotoxicity requires additional studies.

mAbs, eliminate cancer cells involve both granule-dependent and granule independent cellular cytotoxicity. This information represents a platform for developing Fcy-CR-based targeted therapies of virtually any malignancies, as long as therapeutic $\mathrm{mAbs}$ with the appropriate specificity are available. To reach this goal, additional information is needed to optimize Fc $\gamma$-CR and $\mathrm{mAb}$ combination before testing the described strategy in a clinical setting. To this end, investigators will need to accomplish three primary tasks. The first task will be aimed to identify strategies that will increase the pool of therapeutic mAbs capable of redirecting $\mathrm{T}$ cells against cancer cells. The second task should have the objective to determine the best solid tumor to be targeted. The third task should determine in vivo toxicity of Fc $\gamma$-CR-based immunotherapy.

In this context, it is critical to consider the basis of the interaction of therapeutic mAbs with $\mathrm{Fc}$ receptors. The isotype IgG1 is the prevalent subclass of IgG mAbs utilized in the clinic (Table 1). IgG1 mAbs preferentially bind CD16 ${ }^{\text {valine-158-valine }}$ but also CD16 valine-158-phenylalanine variants. They are capable of triggering NK cell and monocyte-mediated ADCC but also antibodydependent cellular phagocytosis, and complement-dependent cytotoxicity. In contrast, IgG2 is also used in mAb therapeutics; however, it elicits significant weaker ADCC since it does not trigger NK cell-mediated cytotoxicity, as compared to IgG1. Nevertheless, they are still capable of eliciting a myeloid cell-mediated cytotoxicity (41). As a consequence, the use of IgG2 therapeutic mAbs in EGFR positive malignancies, and particularly in those with KRAS mutations, may trigger lower antitumor activity than IgG1 mAbs. Interestingly, most subclasses of monomeric mAbs including 
IgG1, IgG3, and IgG4 but not IgG2 display a high-affinity Fc binding to the FcyRI (CD64) leading to the stimulation of a potent myeloid-mediated cytotoxicity and phagocytosis. Unfortunately, CD64-mediated ADCC may have a limited impact on the inhibition of tumor progression since it does not involve NK cells. Given the availability of four IgG2 and three IgG4 therapeutic $\mathrm{mAbs}$, it is likely that investigators will maximize the antitumor effect of the therapeutic mAb of interest by engineering $\mathrm{T}$ cells with the most appropriated Fcy-CR. Since, the CD16-CR is the only molecule today available in the laboratories, in order to identify the best combination of therapeutic mAb with Fcy-CR, there will be a need for developing the CD32 and CD64 CRs to be utilized in additional studies in vitro and in vivo.

It is noteworthy that solid tumors are not an ideal target for immune cells. This is mainly due to the ability of cancer cells to avoid immune cells by utilizing several types of escape mechanisms affecting accessibility, persistence, and function of immune cells in the tumor microenvironment. Compelling evidence suggests that solid tumors do not promote an efficient ADCC since their microenvironment is deficient in NK cells (42) but rich in M2 macrophages endowed with immunosuppressive and proangiogenic functions (43) and regulatory T cells (44). As a consequence, such an anti-inflammatory microenvironment favors tumor progression. Nevertheless, colorectal carcinoma (CRC) represents an interesting exception. Among solid tumors, immune cell infiltration in the CRC microenvironment is associated with improved overall survival even in the presence of known

\section{REFERENCES}

1. Gross G, Waks T, Eshhar Z. Expression of immunoglobulin-T-cell receptor chimeric molecules as functional receptors with antibody-type specificity. Proc Natl Acad Sci U S A (1989) 86(24):10024-8. doi:10.1073/pnas.86. 24.10024

2. Sadelain M, Brentjens R, Rivière I. The promise and potential pitfalls of chimeric antigen receptors. Curr Opin Immunol (2009) 21(2):215-23. doi:10.1016/j. coi.2009.02.009

3. Louis CU, Savoldo B, Dotti G, Pule M, Yvon E, Myers GD, et al. Antitumor activity and long-term fate of chimeric antigen receptor positive $\mathrm{T}$ cells in patients with neuroblastoma. Blood (2011) 118(23):6050-6. doi:10.1182/ blood-2011-05-354449

4. Bridgeman JS, Hawkins RE, Hombach AA, Abken H, Gilham DE. Building better chimeric antigen receptors for adoptive T cell therapy. Curr Gene Ther (2010) 10(2):77-90. doi:10.2174/156652310791111001

5. Ramos CA, Dotti G. Chimeric antigen receptor (CAR)-engineered lymphocytes for cancer therapy. Expert Opin Biol Ther (2011) 11(7):855-73. doi:10.1517/ 14712598.2011 .573476

6. Finney HM, Lawson AD, Bebbington CR, Weir AN. Chimeric receptors providing both primary and costimulatory signaling in $\mathrm{T}$ cells from a single gene product. J Immunol (1998) 161(6):2791-7.

7. Moeller M, Haynes NM, Trapani JA, Teng MW, Jackson JT, Tanner JE, et al. A functional role for CD28 costimulation in tumor recognition by single-chain receptor-modified T cells. Cancer Gene Ther (2004) 11(5):371-9. doi:10.1038/sj. cgt.7700710

8. van der Stegen SJ, Hamieh M, Sadelain M. The pharmacology of secondgeneration chimeric antigen receptors. Nat Rev Drug Discov (2015) 14(7): 499-509. doi:10.1038/nrd4597

9. Kowolik CM, Topp MS, Gonzalez S, Pfeiffer T, Olivares S, Gonzalez N, et al. CD28 costimulation provided through a CD19-specific chimeric antigen receptor enhances in vivo persistence and antitumor efficacy of adoptively transferred T cells. Cancer Res (2006) 66(22):10995-1004. doi:10.1158/ 0008-5472.CAN-06-0160 immunosuppressive cells such as tumor-associated macrophages $(45,46)$, and regulatory $\mathrm{T}$ cells $(44)$. In addition, two lines of evidence suggest that ADCC contributes to the antitumor activity of anti-EGFR mAbs. First, a subset of CRC cells is consistently infiltrated by NK cells $(47,48)$. Second, the presence of a CD16 $16^{\text {valine- }}$ 158-valine predicts favorable clinical responses in CRC patients (32). Based on this information in our opinion, CRC could be an ideal target for assessing the antitumor activity of $\mathrm{Fc} \gamma$-CR T cells.

Finally, to determine the potential toxicity of this treatment, it may be useful to utilize immunocompetent mice bearing a spontaneous or engrafted CRC to be targeted with mouse Fc $\gamma$-CR $\mathrm{T}$ cells in combination with mouse anti-EGFRs mAbs.

\section{AUTHOR CONTRIBUTIONS}

SC, SF, and GS conceived and wrote the manuscript. TS, RA, AC, GL, DL, AV, MIDP, FB, LM, and MP have critically reviewed and revised the manuscript. All authors fully agreed with the manuscript content.

\section{FUNDING}

GS was supported by the Italian Association for Cancer Research (AIRC) IG grant No. 17120. SF was supported by the Grant W81XWH-16-1-0500 awarded by the Department of Defense and by the NIH grant R03 CA175957 awarded by the National Cancer Institute.

10. Savoldo B, Ramos CA, Liu E, Mims MP, Keating MJ, Carrum G, et al. CD28 costimulation improves expansion and persistence of chimeric antigen receptor-modified T cells in lymphoma patients. J Clin Invest (2011) 121(5): 1822-6. doi:10.1172/JCI46110

11. Davila ML, Riviere I, Wang X, Bartido S, Park J, Curran K, et al. Efficacy and toxicity management of $19-28 \mathrm{z}$ CAR T cell therapy in B cell acute lymphoblastic leukemia. Sci Transl Med (2014) 6(224):224ra25. doi:10.1126/ scitranslmed.3008226

12. Koehler H, Kofler D, Hombach A, Abke H. CD28 costimulation overcomes transforming growth factor-beta-mediated repression of proliferation of redirected human CD4+ and CD8+ T cells in an antitumor cell attack. Cancer Res (2007) 67:2265-73. doi:10.1158/0008-5472.CAN-06-2098

13. Kofler DM, Chmielewski M, Rappl G, Hombach A, Riet T, Schmidt A, et al. CD28 costimulation impairs the efficacy of a redirected T-cell antitumor attack in the presence of regulatory $\mathrm{T}$ cells which can be overcome by preventing Lck activation. Mol Ther (2011) 19(4):760-7. doi:10.1038/mt.2011.9

14. Imai C, Mihara K, Andreansky M, Nicholson IC, Pui CH, Geiger TL, et al. Chimeric receptors with $4-1 \mathrm{BB}$ signaling capacity provoke potent cytotoxicity against acute lymphoblastic leukemia. Leukemia (2004) 18(4):676-84. doi:10.1038/sj.leu.2403302

15. Tammana S, Huang X, Wong M, Milone MC, Ma L, Levine BL, et al. 4-1BB and CD28 signaling plays a synergistic role in redirecting umbilical cord blood T cells against B-cell malignancies. Hum Gene Ther (2010) 21(1):75-86. doi:10.1089/hum.2009.122

16. Song DG, Ye Q, Carpenito C, Poussin M, Wang LP, Ji C, et al. In vivo persistence, tumor localization, and antitumor activity of CAR-engineered T cells is enhanced by costimulatory signaling through CD137 (4-1BB). Cancer Res (2011) 71(13):4617-27. doi:10.1158/0008-5472.CAN-11-0422

17. Gilham DE, Debets R, Pule M, Hawkins RE, Abken H. CAR-T cells and solid tumors: tuning T cells to challenge an inveterate foe. Trends Mol Med (2012) 18(7):377-84. doi:10.1016/j.molmed.2012.04.009

18. Hombach AA, Abken H. Costimulation by chimeric antigen receptors revisited the $\mathrm{T}$ cell antitumor response benefits from combined CD28-OX40 signaling. Int J Cancer (2011) 129(12):2935-44. doi:10.1002/ijc.25960 


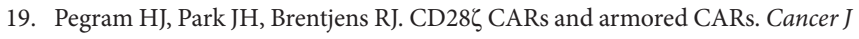
(2014) 20(2):127-33. doi:10.1097/PPO.0000000000000034

20. Pegram HJ, Lee JC, Hayman EG, Imperato GH, Tedder TF, Sadelain M, et al. Tumor-targeted T cells modified to secrete IL-12 eradicate systemic tumors without need for prior conditioning. Blood (2012) 119(18):4133-41. doi:10.1182/blood-2011-12-400044

21. Curran KJ, Seinstra BA, Nikhamin Y, Yeh R, Usachenko Y, van Leeuwen DG, et al. Enhancing antitumor efficacy of chimeric antigen receptor $\mathrm{T}$ cells through constitutive CD40L expression. Mol Ther (2015) 23(4):769-78. doi:10.1038/mt.2015.4

22. Tey SK. Adoptive T-cell therapy: adverse events and safety switches. Clin Transl Immunology (2014) 3(6):e17. doi:10.1038/cti.2014.11

23. Kochenderfer JN, Dudley ME, Feldman SA, Wilson WH, Spaner DE, Maric I, et al. B-cell depletion and remissions of malignancy along with cytokine-associated toxicity in a clinical trial of anti-CD19 chimeric-antigenreceptor-transduced T cells. Blood (2012) 119:2709-20. doi:10.1182/blood2011-10-384388

24. Greco R, Oliveira G, Stanghellini MT, Vago L, Bondanza A, Peccatori J, et al. Improving the safety of cell therapy with the TK-suicide gene. Front Pharmacol (2015) 6:95. doi:10.3389/fphar.2015.00095

25. Weiner LM, Surana R, Wang S. Monoclonal antibodies: versatile platforms for cancer immunotherapy. Nat Rev Immunol (2010) 10:317-27. doi:10.1038/ nri2744

26. Sartore-Bianchi A, Trusolino L, Martino C, Bencardino K, Lonardi S, Bergamo F, et al. Dual-targeted therapy with trastuzumab and lapatinib in treatmentrefractory, KRAS codon 12/13 wild-type, HER2-positive metastatic colorectal cancer (HERACLES): a proof-of-concept, multicentre, open-label, phase 2 trial. Lancet Oncol (2016) 17(6):738-46. doi:10.1016/S1470-2045(16)00150-9

27. Srivastava RM, Lee SC, Andrade Filho PA, Lord CA, Jie HB, Davidson HC, et al. Cetuximab-activated natural killer and dendritic cells collaborate to trigger tumor antigen-specific T-cell immunity in head and neck cancer patients. Clin Cancer Res (2013) 19(7):1858-72. doi:10.1158/1078-0432.CCR-12-2426

28. Wallace PK, Howell AL, Fanger MW. Role of Fc gamma receptors in cancer and infectious disease. J Leukoc Biol (1994) 55(6):816-26.

29. Wang W, Erbe AK, Hank J, Morris ZS, Sondel PM. NK cell-mediated antibody-dependent cellular cytotoxicity in cancer immunotherapy. Front Immunol (2015) 6:368. doi:10.3389/fimmu.2015.00368

30. Clynes RA, Towers TL, Presta LG, Ravetch JV. Inhibitory Fc receptors modulate in vivo cytoxicity against tumor targets. Nat Med (2000) 6(4):443-6. doi:10.1038/74704

31. Koene HR, Kleijer M, Algra J, Roos D, von dem Borne AE, de Haas M. Fc gammaRIIIa-158V/F polymorphism influences the binding of the IgG by natural killer cell Fc gammaRIIIa, independently of the Fc gammaRIIIa48L/R/H phenotype. Blood (1997) 90:1109-14.

32. Bibeau F, Lopez-Crapez E, Di Fiore F, Thezenas S, Ychou M, Blanchard F, et al. Impact of Fcgamma RIIa-Fcgamma RIIIa polymorphisms and KRAS mutations on the clinical outcome of patients with metastatic colorectal cancer treated with cetuximab plus irinotecan. JClin Oncol (2009) 27(7):1122-9. doi:10.1200/JCO.2008.18.0463

33. Albertsson PA, Basse PH, Hokland M, Goldfarb RH, Nagelkerke JF, Nannmark U, et al. NK cells and the tumour microenvironment: implications for NK-cell function and anti-tumour activity. Trends Immunol (2003) 24(11):603-9. doi:10.1016/j.it.2003.09.007

34. Pagès F, Berger A, Camus M, Sanchez-Cabo F, Costes A, Molidor R, et al. Effector memory T cells, early metastasis, and survival in colorectal cancer. N Engl J Med (2005) 353(25):2654-66. doi:10.1056/NEJMoa051424

35. Clémenceau B, Congy-Jolivet N, Gallot G, Vivien R, Gaschet J, Thibault G, et al. Antibody-dependent cellular cytotoxicity (ADCC) is mediated by genetically modified antigen-specific human T lymphocytes. Blood (2006) 107(12):4669-77. doi:10.1182/blood-2005-09-3775

36. Ochi F, Fujiwara H, Tanimoto K, Asai H, Miyazaki Y, Okamoto S, et al. Genemodified human $\alpha / \beta-\mathrm{T}$ cells expressing a chimeric $\mathrm{CD} 16-\mathrm{CD} 3 \zeta$ receptor as adoptively transferable effector cells for anticancer monoclonal antibody therapy. Cancer Immunol Res (2014) 2(3):249-62. doi:10.1158/2326-6066. CIR-13-0099-T

37. Kudo K, Imai C, Lorenzini P, Kamiya T, Kono K, Davidoff AM, et al. T lymphocytes expressing a CD16 signaling receptor exert antibody-dependent cancer cell killing. Cancer Res (2014) 74(1):93-103. doi:10.1158/0008-5472. CAN-13-1365

38. D’Aloia MM, Caratelli S, Palumbo C, Battella S, Arriga R, Lauro D, et al. $\mathrm{T}$ lymphocytes engineered to express a CD16-chimeric antigen receptor redirect T-cell immune responses against immunoglobulin G-opsonized target cells. Cytotherapy (2016) 18(2):278-90. doi:10.1016/j.jcyt.2015. 10.014

39. Wickham TJ, Lee GM, Titus JA, Sconocchia G, Bakács T, Kovesdi I, et al. Targeted adenovirus-mediated gene delivery to T cells via CD3. J Virol (1997) 71(10):7663-9.

40. Tanaka H, Fujiwara H, Ochi F, Tanimoto K, Casey N, Okamoto S, et al. Development of engineered $\mathrm{T}$ cells expressing a chimeric $\mathrm{CD} 16-\mathrm{CD} 3 \zeta$ receptor to improve the clinical efficacy of mogamulizumab therapy against adult T cell leukemia. Clin Cancer Res (2016) 22:4405-16. doi:10.1158/1078-0432. CCR-15-2714

41. Schneider-Merck T, Lammerts van Bueren JJ, Berger S, Rossen K, van Berkel PH, Derer S, et al. Human IgG2 antibodies against epidermal growth factor receptor effectively trigger antibody-dependent cellular cytotoxicity but, in contrast to IgG1, only by cells of myeloid lineage. J Immunol (2010) 184:512-20. doi:10.4049/jimmunol.0900847

42. Sconocchia G, Arriga R, Tornillo L, Terracciano L, Ferrone S, Spagnoli GC. Melanoma cells inhibit NK cell functions. Cancer Res (2012) 72(20):5428-9. doi:10.1158/0008-5472.CAN-12-1181

43. Allavena P, Sica A, Garlanda C, Mantovani A. The Yin-Yang of tumorassociated macrophages in neoplastic progression and immune surveillance. Immunol Rev (2008) 222:155-61. doi:10.1111/j.1600-065X.2008.00607.x

44. Frey DM, Droeser RA, Viehl CT, Zlobec I, Lugli A, Zingg U, et al. High frequency of tumor-infiltrating FOXP3(+) regulatory $\mathrm{T}$ cells predicts improved survival in mismatch repair-proficient colorectal cancer patients. Int $J$ Cancer (2010) 126(11):2635-43. doi:10.1002/ijc.24989

45. Sconocchia G, Zlobec I, Lugli A, Calabrese D, Iezzi G, Karamitopoulou E, et al. Tumor infiltration by FcyRIII (CD16)+ myeloid cells is associated with improved survival in patients with colorectal carcinoma. Int J Cancer (2011) 128(11):2663-72. doi:10.1002/ijc.25609

46. Sconocchia G, Eppenberger-Castori S, Zlobec I, Karamitopoulou E, Arriga R, Coppola A, et al. HLA class II antigen expression in colorectal carcinoma tumors as a favorable prognostic marker. Neoplasia (2014) 16(1):31-42. doi:10.1593/neo.131568

47. Sconocchia G, Eppenberger S, Spagnoli GC, Tornillo L, Droeser R, Caratelli S, et al. NK cells and T cells cooperate during the clinical course of colorectal cancer. Oncoimmunology (2014) 3(8):e952197. doi:10.4161/ 21624011.2014.95219

48. Coppola A, Arriga R, Lauro D, Del Principe MI, Buccisano F, Maurillo L, et al. NK cell inflammation in the clinical outcome of colorectal carcinoma. Front Med (2015) 26(2):33. doi:10.3389/fmed.2015.00033

Conflict of Interest Statement: The authors declare that the research was conducted in the absence of any commercial or financial relationships that could be construed as a potential conflict of interest.

Copyright ( 2017 Caratelli, Sconocchia, Arriga, Coppola, Lanzilli, Lauro, Venditti, Del Principe, Buccisano, Maurillo, Ferrone and Sconocchia. This is an open-access article distributed under the terms of the Creative Commons Attribution License (CC BY). The use, distribution or reproduction in other forums is permitted, provided the original author(s) or licensor are credited and that the original publication in this journal is cited, in accordance with accepted academic practice. No use, distribution or reproduction is permitted which does not comply with these terms. 